\title{
Atmospheric sulphuric acid and neutral cluster measurements using CI-APi-TOF
}

\author{
T. Jokinen ${ }^{1}$, M. Sipilä ${ }^{1}$, H. Junninen ${ }^{1}$, M. Ehn ${ }^{2}$, G. Lönn ${ }^{1}$, J. Hakala ${ }^{1}$, T. Petäjä ${ }^{1}$, R. L. Mauldin III ${ }^{1,3}$, M. Kulmala ${ }^{1}$, \\ and D. R. Worsnop ${ }^{1,4,5,6}$ \\ ${ }^{1}$ Department of Physics, P.O. Box 64, 00014, University of Helsinki, Finland \\ ${ }^{2}$ Institute for Energy and Climate Research, Forschungszentrum Jülich, Germany \\ ${ }^{3}$ Institute for Arctic and Alpine Research, University of Colorado, Boulder, CO 80309, USA \\ ${ }^{4}$ University of Eastern Finland, P.O. Box 1627, 70211 Kuopio, Finland \\ ${ }^{5}$ Finnish Meteorological Institute, 00880 Helsinki, Finland \\ ${ }^{6}$ Aerodyne Research Inc., Billerica, MA 01821, USA \\ Correspondence to: T. Jokinen (tuija.jokinen@helsinki.fi)
}

Received: 20 October 2011 - Published in Atmos. Chem. Phys. Discuss.: 6 December 2011

Revised: 17 April 2012 - Accepted: 23 April 2012 - Published: 9 May 2012

\begin{abstract}
The first ambient measurements using nitrate ion based Chemical Ionization with the Atmospheric Pressure interface Time-Of-Flight mass spectrometer (CI-APi-TOF) for sulphuric acid and neutral cluster detection are presented. We have found CI-APi-TOF a highly stable and sensitive tool for molecular sulphuric acid detection. The lowest limit of detection for sulphuric acid was determined to be $3.6 \times 10^{4}$ molecules $\mathrm{cm}^{-3}$ for $15 \mathrm{~min}$ averaging. Signals from sulphuric acid clusters up to tetramer containing ammonia were also obtained but these were found to result from naturally charged clusters formed by ion induced clustering in the atmosphere during nucleation. Opposite to earlier studies with cluster mass spectrometers, we had no indication of neutral clusters. The reason is either less efficient charging of clusters in comparison to molecular sulphuric acid, or the low concentration of neutral clusters at our measurement site during these particular nucleation events. We show that utilizing high resolution mass spectrometry is crucial in separating the weak sulfuric acid cluster signal from other compounds.
\end{abstract}

\section{Introduction}

Nucleation of new particles is one of the main sources of cloud condensation nuclei in the Earth's atmosphere contributing up to $\sim 50 \%$ to the global $\mathrm{CCN}$ budget (Merikanto et al., 2010). With the exception of certain coastal areas
(O'Dowd et al., 2002), the initial steps of nucleation require the presence of sulphuric acid (Paasonen et al., 2010; Sipilä et al., 2010; Zhao et al., 2010). Sulphuric acid $\left(\mathrm{H}_{2} \mathrm{SO}_{4}\right)$, however, does not nucleate itself under typical atmospheric conditions, requiring additional vapours. Based on recent laboratory experiments (Kirkby et al., 2011), at ambient $\mathrm{H}_{2} \mathrm{SO}_{4}$ concentrations, water could serve as a binary partner under upper tropospheric conditions. At boundary layer temperatures, the evaporation of clusters containing only sulphuric acid and water is too fast to allow freshly nucleated particles to grow, and thus additional species are required. Kirkby et al. (2011) measured ammonia and dimethylamine from the charged clusters formed by ion induced nucleation, and concluded that they are plausible candidates for stabilizing also neutral clusters at lower atmospheric conditions. The enhancing effect of amines on new particle formation was also observed in laboratory studies by Berndt et al. (2010) and Benson et al. (2011). Ammonia has been observed to also exist in atmospheric ion clusters together with sulphuric acid (Ehn et al., 2010). Concentrations of amines in the atmosphere are orders of magnitudes lower than that of ammonia, however, amines can bind the cluster much more strongly (Kurtén et al., 2008) and thus even ppt levels of amines can be enough to account for atmospheric nucleation rates (Petäjä et al., 2011).

Nucleation is a frequent phenomenon occurring approximately $30 \%$ of the days in Hyytiälä (e.g. Kulmala et al., 2010) and similarly to most continental sites it is connected 
to the presence of sulphuric acid (e.g. Paasonen et al., 2010 and Weber et al., 1996). Suggested mechanisms of nucleation include both neutral and ion assisted pathways. Kulmala et al. (2007) suggested nucleation processes to be initiated by activation of neutral clusters while modelling studies by $\mathrm{Yu}$ and Turco $(2008,2011)$ suggest that ions play a crucial role in boreal forest nucleation. Recent studies by Manninen et al. (2009) and Kulmala et al. (2010) find neutral nucleation dominant in the atmosphere, while laboratory experiments by Sipilä et al. (2010) support the conclusion that neutral nucleation involving sulphuric acid can proceed fast enough to account for atmospheric observations. On the other hand, the experiments by Petäjä et al. (2011) and Kirkby et al. (2011) demonstrated that besides sulphuric acid, ternary vapours are required. Kirkby et al. (2011) also confirmed the existence of a physical nucleation mechanism involving ions. That experiment was, however, performed under conditions not representative of the boreal forest boundary layer. Recent progress in mass spectrometry has made direct measurements of ion induced nucleation possible (Ehn et al., 2010; Junninen et al., 2010; Kirkby et al., 2011). With our new instrument, the CI-APi-TOF, we aim to investigate the initial steps of neutral nucleation and elucidate the role of sulphuric acid, ions and stabilizing compounds in atmospheric aerosol nucleation.

The problem in understanding the molecular steps controlling neutral nucleation is that, while the detection of neutral clusters is made possible by the recent development of condensation particle counting technology (Kulmala et al., 2007; Sipilä et al., 2008; Iida et al., 2009; Vanhanen et al., 2011), the measurement of their chemical composition is extremely difficult. For a mass spectrometer, the neutral cluster needs to be charged and that charging process initiates several problems. First, typical ion sources generate a vast amount of ions and ion clusters from atmospheric trace gases (Asmi et al., 2009). These artificially generated ion clusters obscure the signal from ambient neutral clusters charged upon collisions with the charger ions, thereby hindering their identification. This problem can be partially solved by utilizing the highly selective chemical ionization technique (Eisele and Hanson, 2000; Hanson and Eisele, 2002; Hanson and Lovejoy, 2006; Zhao et al., 2010; Jiang et al., 2011; Petäjä et al., 2011). This is also the approach used in the present study. A problem associated with selective ionization is that the proton affinity of a neutral cluster, composed of sulphuric acid and stabilizing compounds, can be very different from that of a pure sulphuric acid molecule. Therefore those clusters do not necessarily charge exchange upon collision with charger ions (Kurtén et al., 2011). Nevertheless, if a cluster becomes charged, its stability may change and it can lose, depending on its size, partially or completely it's binary or ternary constituents. In experiments by Junninen et al. (2010) and Kirkby et al. (2011) it was found that negatively charged clusters containing less than three molecules of sulphuric acid associated with the bisulphate ion $\left(\mathrm{HSO}_{4}^{-}\right)$did not accommodate any other species while clusters containing more than four sulphuric acid molecules always contained base molecules at lower tropospheric temperatures. Therefore, direct measurement of the true molecular composition of neutral clusters is not possible by means of chemical ionization as some information will be lost upon charging. Nevertheless, such measurements can still yield significant new information on the mechanics of nucleation in the atmosphere.

Imbued with the first successful field measurements by Zhao et al. (2010) and Jiang et al. (2011) who were able to detect up to tetramer clusters of sulphuric acid during nucleation events, we constructed a Chemical Ionization (CI) source and combined it with an Atmospheric Pressure interface Time-Of-Flight mass spectrometer (APi-TOF, Tofwerk AG, Thun, Switzerland and Aerodyne Research Inc., USA). The aim of this study was to apply this instrument, the CIAPi-TOF, to measure molecular sulphuric acid as well as sulphuric acid containing clusters in ambient air at the Hyytiälä boreal forest field site, in southern Finland.

\section{Methods}

\subsection{Instrumentation}

The CI-APi-TOF instrument consists of three main components. These components are

1. a specially designed inlet for chemical ionization at the ambient pressure (CI),

2. an atmospheric pressure interface (APi) and

3. a time-of-flight mass spectrometer (TOF).

The APi-TOF is well described elsewhere (Junninen et al., 2010). The design of the CI-inlet is similar to one described by Eisele and Tanner (1993), and by Kurtén et al. (2011). The sample is drawn in though a $3 / 4^{\prime \prime}$ stainless steel tube with a flow rate of $10 \mathrm{lpm}$. Nitrate ions are created by exposing clean air containing nitric acid $(20 \mathrm{lpm})$ to alpha radiation from $10 \mathrm{MBq}^{241} \mathrm{Am}$ source. This sheath flow is then introduced in an ion reaction tube concentric to the sample flow. Nitrate ions in the sheath flow are directed into the sample flow by means of an electric field. The interaction time between ions and sample gas is approximately $200 \mathrm{~ms}$.

Ionization in the CI-system occurs at ambient pressure via proton transfer between nitrate ions or its cluster with nitric acid $\left(\mathrm{NO}_{3}^{-} \cdot\left(\mathrm{HNO}_{3}\right)_{n}\right)$ and sulphuric acid $\left(\mathrm{H}_{2} \mathrm{SO}_{4}\right)$ producing bisulphate ion - nitric acid clusters $\left(\mathrm{HSO}_{4}^{-} \cdot \mathrm{HNO}_{3}\right)$ and neutral nitric acid $\left(\left(\mathrm{HNO}_{3}\right)_{n}\right)$ :

$$
\begin{aligned}
\mathrm{H}_{2} \mathrm{SO}_{4} & +\mathrm{NO}_{3}^{-} \cdot\left(\mathrm{HNO}_{3}\right)_{n, n=0-2} \\
& \rightarrow \mathrm{HSO}_{4}^{-} \cdot \mathrm{HNO}_{3}+\left(\mathrm{HNO}_{3}\right)_{n, n=0-2}
\end{aligned}
$$

The chemically ionized sample enters the instrument through a critical orifice with a flow rate of $\sim 0.8 \mathrm{lpm}$. The ions are 


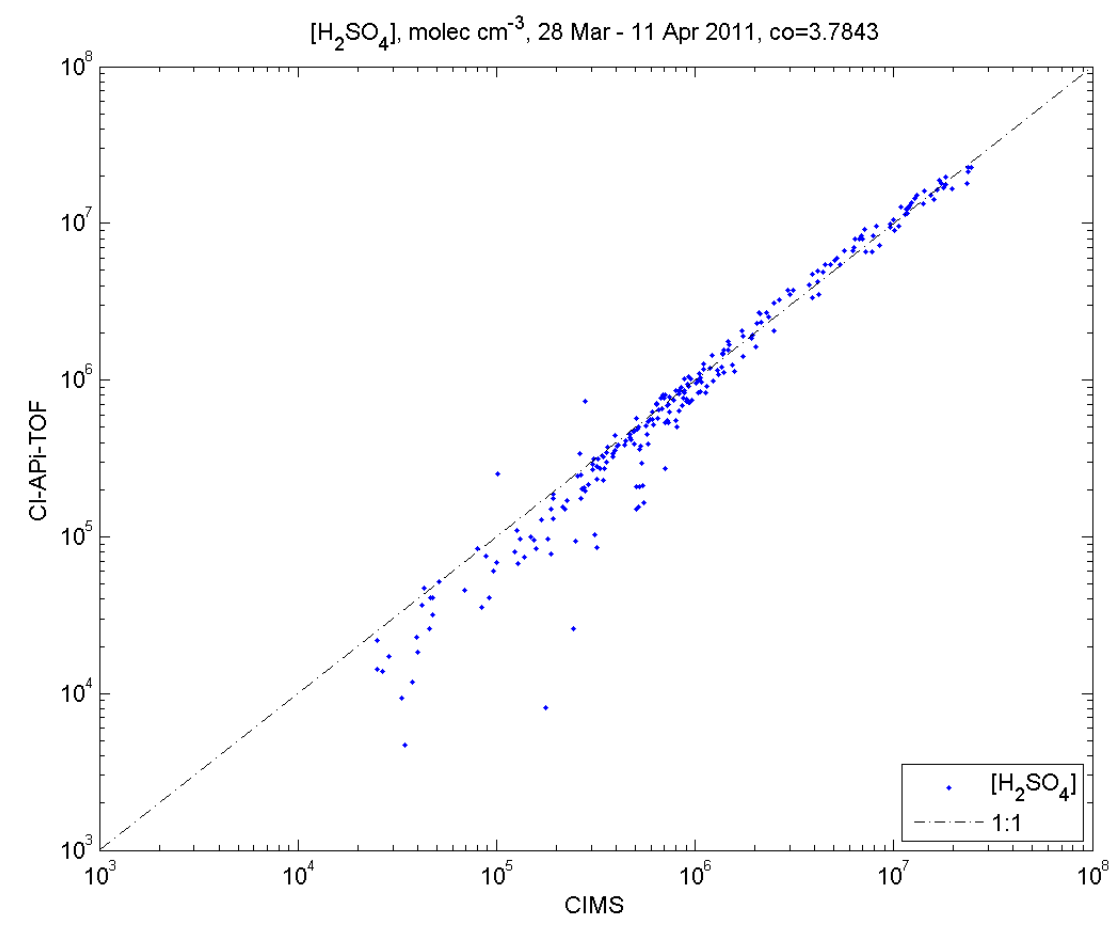

Fig. 1. Correlation between sulphuric acid concentrations measured with the CI-APi-TOF (using a standard calibration coefficient $C=$ $5 \times 10^{9}$, Mauldin III et al., 1999) and calibrated CIMS from 28 March to 11 April 2011. Data sets are 60 min averages. The CI-APi-TOF data have been multiplied by the average ratio between the two data sets, 3.78. This factor includes diffusion losses in the CI-APi-TOF sample line, and is used when converting the CI-APi-TOF signals to concentrations.

then guided through the differentially pumped APi and further to the TOF for separation according to their $\mathrm{m} / \mathrm{z}$. The final pressure inside the TOF is typically $10^{-6}$ mbar.

Clusters in Reaction (R1) partially decompose in the vacuum of the APi-TOF. The sulphuric acid concentration (in molec $\mathrm{cm}^{-3}$ ) measured with the CI-APi-TOF is calculated from the measured ion signals according to:

$$
\begin{aligned}
& {\left[\mathrm{H}_{2} \mathrm{SO}_{4}\right]=} \\
& \quad \frac{\mathrm{HSO}_{4}^{-}+\mathrm{HSO}_{4}^{-} \cdot \mathrm{HNO}_{3}}{\mathrm{NO}_{3}^{-}+\mathrm{HNO}_{3} \cdot \mathrm{NO}_{3}^{-}+\mathrm{HNO}_{3} \cdot\left(\mathrm{HNO}_{3}\right) \mathrm{NO}_{3}^{-}} \cdot C,
\end{aligned}
$$

where $C$ is the calibration coefficient. Unfortunately, the current system has not been directly calibrated, however the calibration coefficient of $5 \times 10^{9}$ molec $\mathrm{cm}^{-3}$ determined for a CI-source similar to the present one (Mauldin III et al., 1999) was applied at the first stage of the data conversion. We also performed an indirect calibration by running our instrument next to a calibrated CIMS in Hyytiälä for ca. 2 weeks (Fig. 1). From this inter-comparison an additional factor of 3.78 was obtained yielding a final calibration coefficient of $C=1.89 \times 10^{10}$ molec cm $^{-3}$. As the inter-comparison was performed with CI-APi-TOF having a $60 \mathrm{~cm}$ long $3 / 4^{\prime \prime}$ sample tube in front of it, the diffusion losses in the sample tube are absorbed in the final calibration coefficient.

The sensitivity of the instrument was also studied. The CIAPi-TOF provides a high signal-to-noise ratio and therefore it can achieve very low detection limits. Most of the background originates from electronic noise but a minor contribution can result from heavier particles with high $\mathrm{m} / \mathrm{z}$ (>3000 Th) having longer time-of-flight than the reciprocal of the pulsing frequency $(12000 \mathrm{~Hz})$. The limit of detection (LOD) for sulfuric acid monomer measured with the CI-APi-TOF is $3.60 \times 10^{4}$ molec $\mathrm{cm}^{-3}$ (15 min integration) and it is defined as three times the standard deviation of the background. This LOD is equivalent to that of earlier CIMS instruments. As this value incorporates the diffusion losses in the sample tube, the loss corrected LOD is closer to $2 \times 10^{4} \mathrm{molec} \mathrm{cm}^{-3}$.

\subsection{Field site}

The measurements presented here were carried out at Hyytiälä Forestry Field Station (SMEAR II) located in Juupajoki, Southern Finland during HydeSpring2011 field campaign. Both neutral cluster and naturally charged sulphuric acid measurements were conducted simultaneously between 14 March and 11 April 2011.

\subsection{Experimental setup and ambient measurements}

Two APi-TOF instruments were deployed to measure gas phase sulphuric acid at the same location. The CI-APi-TOF was set to measure neutral sulphuric acid molecules and 
clusters. The second APi-TOF at the site was set up to measure naturally charged ambient molecules and clusters without the use of any ionizing method. In the atmosphere, cosmic radiation and radioactive decay produce primary ions such as $\mathrm{N}_{2}^{+}, \mathrm{O}_{2}^{+}, \mathrm{O}_{2}^{-}$and $\mathrm{H}_{3} \mathrm{O}^{+}$which subsequently collide with trace gases resulting in charge transfer reactions. Charge will cascade in a series of collisions towards lowest proton affinities (negative ions). In atmosphere this charge transfer process effectively stops at the bisulphate ion $\left(\mathrm{HSO}_{4}^{-}\right)$. Bisulphate ions immediately form clusters with $\mathrm{H}_{2} \mathrm{SO}_{4}$. Clusters containing three or more sulphuric acid molecules associated with the bisulphate ion can also contain e.g. ammonia or amines (Ehn et al., 2010; Kirkby et al., 2011). As naturally charged ions and ion clusters are also sampled with the CI-APi-TOF, measurements from the normal APi-TOF operating in parallel provide information on the contribution of these naturally charged ions to the signals measured with the CI-APi-TOF. In addition, to quantifying the effect of naturally charged ions, the CI-APi-TOF was operated without the ${ }^{241} \mathrm{Am}$ source installed for a few days and the spectra between the two instruments were compared. Introduction of nitrate ions should not affect the penetration of naturally charged ions.

Aerosol size distributions were measured with a Differential Mobility Particle Sizer (DMPS). The system (Aalto et al., 2001) measures particles from $3 \mathrm{~nm}$ to about $950 \mathrm{~nm}$ in diameter. The aerosol size distribution was used to classify the days in terms of new particle formation.

\subsection{Data analysis}

Data analysis was performed using Matlab (version 7.10.0.499, R2010a) based program tofTools (Junninen et al., 2010). Before mass calibration signals were averaged over $60 \mathrm{~min}$. Mass calibration was performed using three known masses that are always dominant in the spectrum, nitrate ion (or its isotope) and it's dimer and trimer $\left(\mathrm{NO}_{3}^{-}\right.$, $\left.\mathrm{HNO}_{3} \cdot \mathrm{NO}_{3}^{-},\left(\mathrm{HNO}_{3}\right)_{2} \cdot \mathrm{NO}_{3}^{-}\right)$. The resolving power is approximately $3600 \mathrm{Th} \mathrm{Th}^{-1}$ for over $45 \mathrm{Th}$ and in lower massto-charge ratios it is slightly lower for ideal peak fitting.

\section{Results and discussion}

\subsection{Peak identification}

The CI-APi-TOF signals are identified by defining the exact mass of the compounds of interest and their possible isotopic patterns. The advantage of the CI-APi-TOF is that even at extremely low sulphuric acid cluster concentrations, the high resolution makes it possible to separate the cluster signal from other closely located peaks. This means the cluster signal can be reliably separated from residual peaks possibly overlapping the original cluster signal, giving more accurate information of the existence and concentrations of clusters in the atmosphere.

The high resolution spectrum for deprotonated sulphuric acid monomer $\mathrm{HSO}_{4}^{-}$, dimer $\mathrm{H}_{2} \mathrm{SO}_{4} \cdot \mathrm{HSO}_{4}^{-}$, trimer $\left(\mathrm{H}_{2} \mathrm{SO}_{4}\right)_{2} \cdot \mathrm{HSO}_{4}^{-}$, and tetramer $\left(\mathrm{H}_{2} \mathrm{SO}_{4}\right)_{3} \cdot \mathrm{HSO}_{4}^{-}$measured with the CI-APi-TOF on 30 March 2011 at 10:00 a.m. is presented in Fig. 2. The most abundant signal is sulphuric acid monomer at $96.9601 \mathrm{Th}$, followed by the dimer $(194.9275 \mathrm{Th})$, trimer $(292.8949 \mathrm{Th})$ and tetramer (390.8622 Th), respectively. At integer $\mathrm{m} / z$ 97 Th only the monomear signal is detected with no interfering compounds. The sulphuric acid dimer is the dominant ion present at integer $\mathrm{m} / \mathrm{z} 195 \mathrm{Th}$, but almost half of the signal consists of other compounds partly extending over the dimer signal. In case of the trimer and the tetramer these other compounds are already predominant. Sulphuric acid trimer can still be dependably separated but in case of the tetramer longer integration time $(>2 \mathrm{~h})$ is needed to reliably separate it from the interfering signals.

Identification of the compounds overlapping the cluster signals of interest is challenging but we are able to narrow down a group of possible candidates with certain elemental compositions. Fluorinated compounds are one possibility that may originate from the PTFE-tubing used to carry sheath flow to the inlet. An example of this is the contaminant peak at $\mathrm{m} / \mathrm{z} 195 \mathrm{Th}$. This peak has no diurnal cycle (Fig. 3) and it has the same exact mass than a fluorinated compound $\mathrm{C}_{4} \mathrm{HF}_{6} \mathrm{O}_{2}^{-}$, (possibly hexafluorobutanoate). When moving to higher $\mathrm{m} / \mathrm{z}$ 's the number of possible combinations of elemental compositions increases rapidly. At $293 \mathrm{Th}$, potential elemental compositions for the largest peak are for example $\mathrm{C}_{6} \mathrm{H}_{8} \mathrm{~F}_{7} \mathrm{O}_{5}^{-}, \mathrm{C}_{9} \mathrm{H}_{7} \mathrm{O}_{4} \mathrm{~F}_{6}^{-}$or $\mathrm{C}_{8} \mathrm{H}_{9} \mathrm{O}_{10} \mathrm{~N}_{2}^{-}$. This peak has a strong diurnal cycle (Fig. 3 ) and therefore the signal more likely originates from atmosphere $\left(\mathrm{C}_{8} \mathrm{H}_{9} \mathrm{O}_{10} \mathrm{~N}_{2}^{-}\right)$rather than the instrument's surfaces that are kept at constant temperature. For the peaks at 391 Th there are already dozens of possibilities, from simple carbohydrates to complicated fluorinated or nitrogen containing compounds, within $\pm 0.001 \mathrm{Th}$.

\subsection{Neutral cluster concentration}

As an example of neutral sulphuric acid and sulphuric acid cluster concentrations we chose two strong new particle formation event days observed on 29 and 30 March 2011. Since sulphuric acid is mainly produced photochemically, a distinct diurnal pattern is apparent with maximum measured values reaching up to $7 \times 10^{6}$ molec $\mathrm{cm}^{-3}$. We measured naturally charged sulphuric acid using a second APi-TOF without any additional ionization method for comparison with the CIAPi-TOF neutral cluster measurements. The DMPS instrument was used to measure particle size distribution to detect new particle formation.

Both APi-TOF instruments were first run without chargers to calibrate their relative signal response. After adding the ionization source, the CI-APi-TOF results were then 

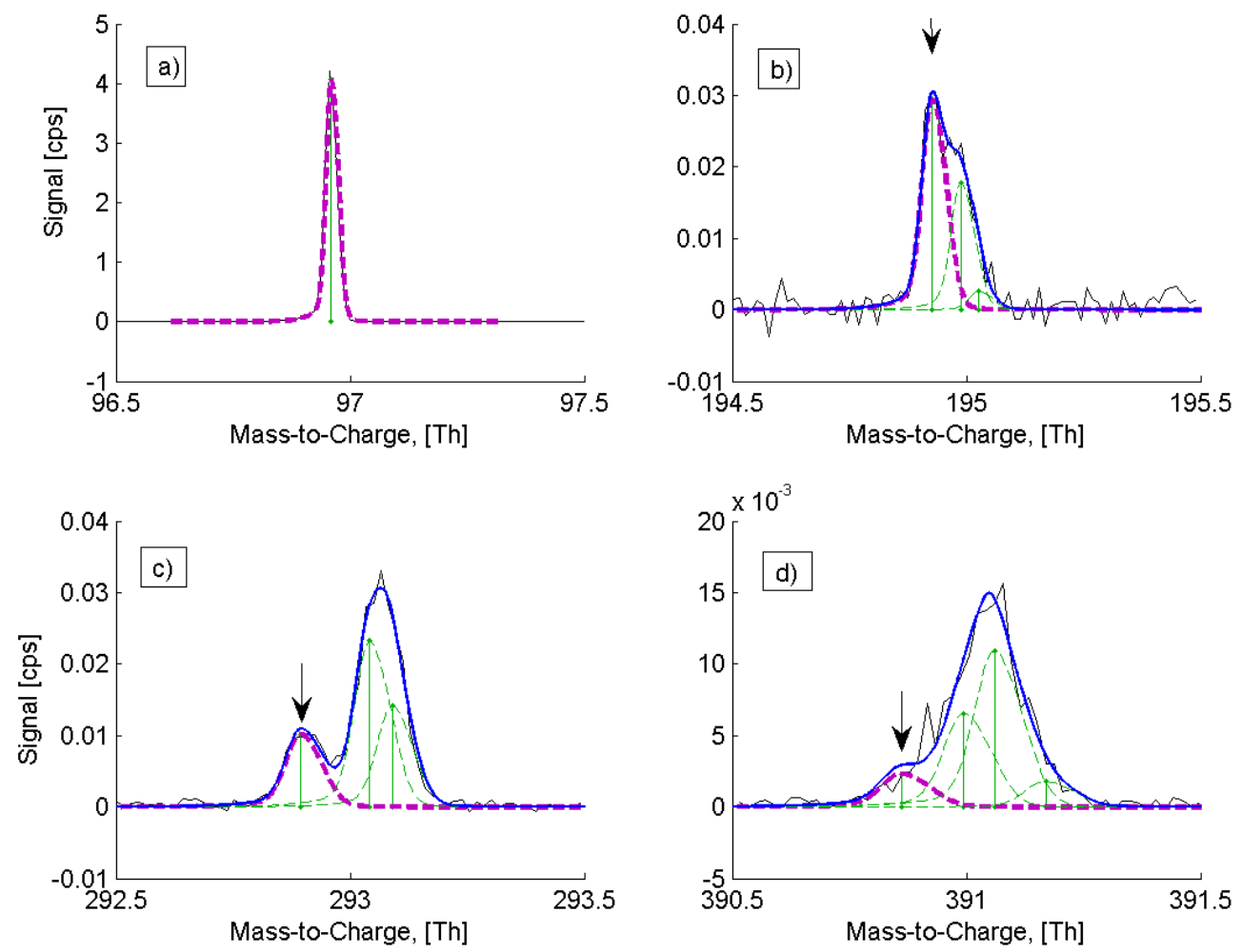

Fig. 2. Peak fitting for sulphuric acid monomer (a), dimer (b), trimer (c) and tetramer (d) clusters at integer mass $97 \mathrm{Th}, 195 \mathrm{Th}, 293 \mathrm{Th}$ and $391 \mathrm{Th}$ on 30 March 2011 at 10:00 a.m. measured with the CI-APi-TOF. The dashed purple lines correspond to the sulphuric acid signals. Isotopic patterns are not provided in the figure but were used to confirm accurate peak identification in addition to the exact masses. Signals are averaged over $120 \mathrm{~min}$.

compared with naturally charged ion spectra measured on 29 and 30 March. Figure 3 presents results when only integer mass resolution data considered (green), the total signal intensity of identified sulphuric acid clusters (blue) and the contribution of naturally charged ions to the total signal (red). Also the signal from the main interfering compound at the integer mass is presented (black). When only one single peak is present, as in the case of sulphuric acid monomer, integer mass data could be used for determination of concentrations. But as seen in Fig. 2, the impact of non-sulphuric compounds overlapping nearly all cluster signalsis major. Indeed, reliable separation of the ammonia containing sulphuric acid tetramer (integer $\mathrm{m} / \mathrm{z}, 408 \mathrm{Th}$ ) was rarely possible. However, though the signals from $408 \mathrm{Th}$ should be taken with a grain of salt, they are presented to illustrate a clear ion signal was observed with the APi-TOF. Using integer mass data only (Fig. 3), one could say that neutral sulphuric acid clusters are present at all times since the CI-APi-TOF cluster signal exceeds the signal estimated to originate from naturally charged ions. The presence of neutral clusters becomes highly unclear when peak fitting is done using the exact mass and the cluster signal has been separated from overlapping peaks.

Figure 4 demonstrates this effect even further by presenting sulphuric acid cluster signals in the beginning of the event on 30 March at 10:00 a.m. when all cluster signals were clearly visible. The figure shows that the only neutral compound that becomes charged using $\mathrm{NO}_{3}^{-}$as the reagent ion is the sulphuric acid monomer which produces a clearly larger signal than the corresponding natural ion signal. Neutral sulphuric acid clusters do not produce strong enough signals to be separable from the signals from naturally charged clusters. In all cases the expected ion contribution to the signal is, within measurement accuracy, equal to the signal from the CI-APi-TOF.

These data are contradictory to the results presented by Zhao et al. (2010) and Jiang et al. (2011) who reported observations of neutral sulphuric acid clusters during nucleation up to the tetramer with concentrations ranging around $10^{4} \mathrm{~cm}^{-3}$. One reason for the disagreement could be that in our casethe signal from naturally charged ions, if converted to concentration (assuming the same calibration coefficient as for monomer) would be around $5 \times 10^{4} \mathrm{~cm}^{-3}$ for both the dimer and trimer. For the tetramer and its cluster with ammonia, the concentration would be in the sub- $10^{4} \mathrm{~cm}^{-3}$ range. If the concentrations of neutral clusters are lower, reliable separation of them from the data is not possible. To get rid of the ion-induced background in future experiments, implementation of an ion filter in front of the CI-inlet will be necessary. 

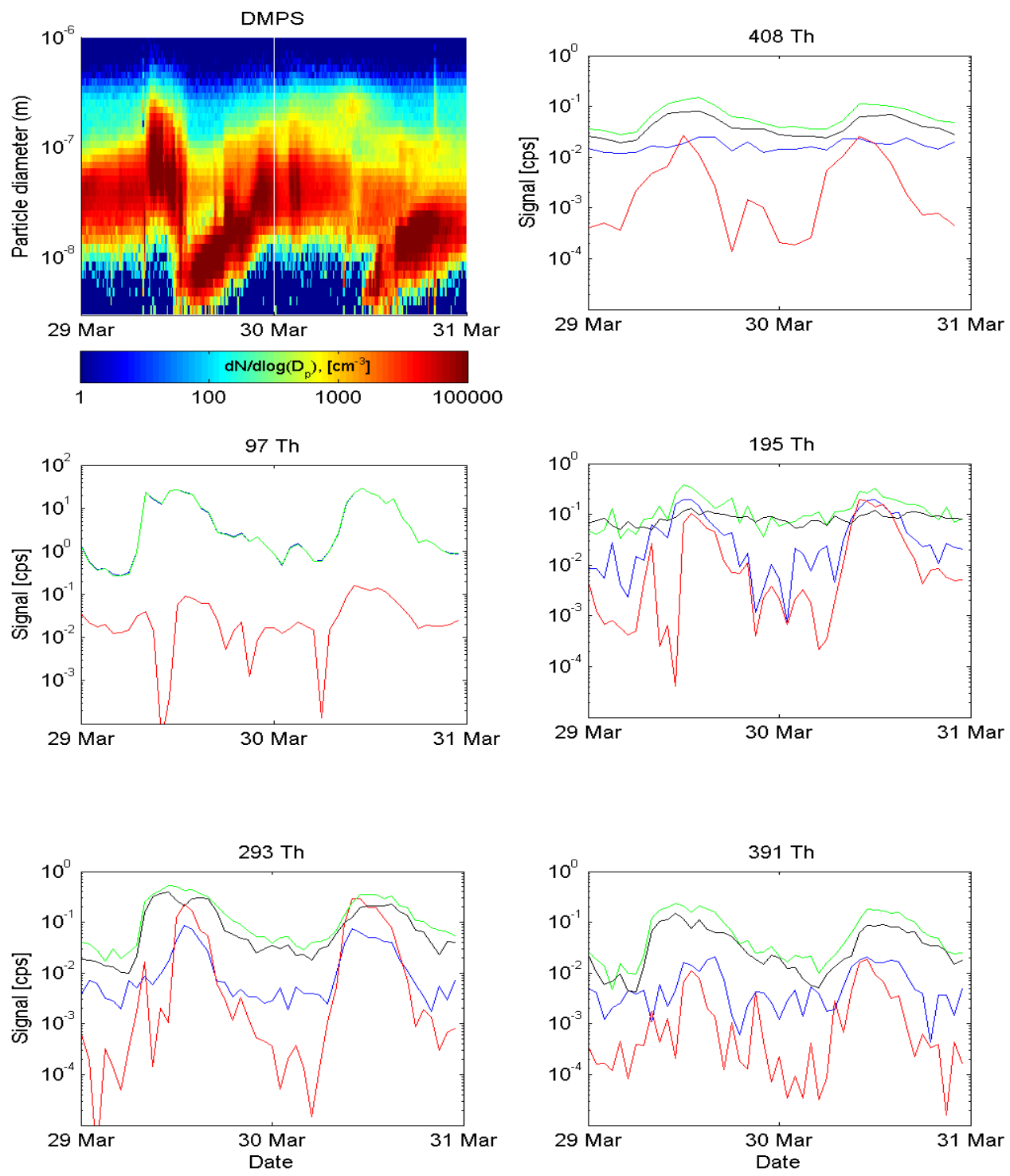

Detected Sulphuric Acid

Fig. 3. Particle and ion concentrations $\left(\mathrm{cm}^{-3}\right)$ measured at Hyytiälä site on 29 and 30 March 2011. Particle size distribution measured with DMPS is shown in the upper left. Other pictures correspond to sulphuric acid monomer (97 Th), dimer (195 Th), trimer (293 Th), tetramer (391 Th) and ammonia-tetramer (408 Th). In case of ammonia-tetramer, the overlapping peaks were such numerous that the reliability of the determination of the signal is most of the time questionable. The blue lines represent neutral sulphuric acid measurements using the CI-APiTOF. The red lines represent naturally charged sulphuric acid measurements using the APi-TOF without accessory ionizing method. The green lines represent the integer mass measured with the CI-APi-TOF that includes both the sulphuric acid and the overlapping compound signals. The black lines represent the signal originating from the strongest overlapping signal at the same integer mass. Most of the CI-APiTOF signal can clearly be explained by the sampled naturally charged ions.

Our results cannot be explained by the findings of Petäjä et al. (2011) either who, as a result of a laboratory experiments, reported close to collision limit formation of sulphuric acid dimers. To explain that observation they suggested that a stabilizing compound $\mathrm{X}$ with binding properties similar to dimethyl amine and a concentration on the order of $10^{7}-10^{8}$ molec $\mathrm{cm}^{-3}$ needs to be present in the system. Our signal from the neutral sulphuric acid dimer was never clearly separable from the signal due to the naturally charged dimer. Thus, the neutral dimer concentration in Hyytiälä during nucleation events seems to be lower than a few $10^{4} \mathrm{~cm}^{-3}$. During the two days presented in Fig. 3, the sulphuric acid 


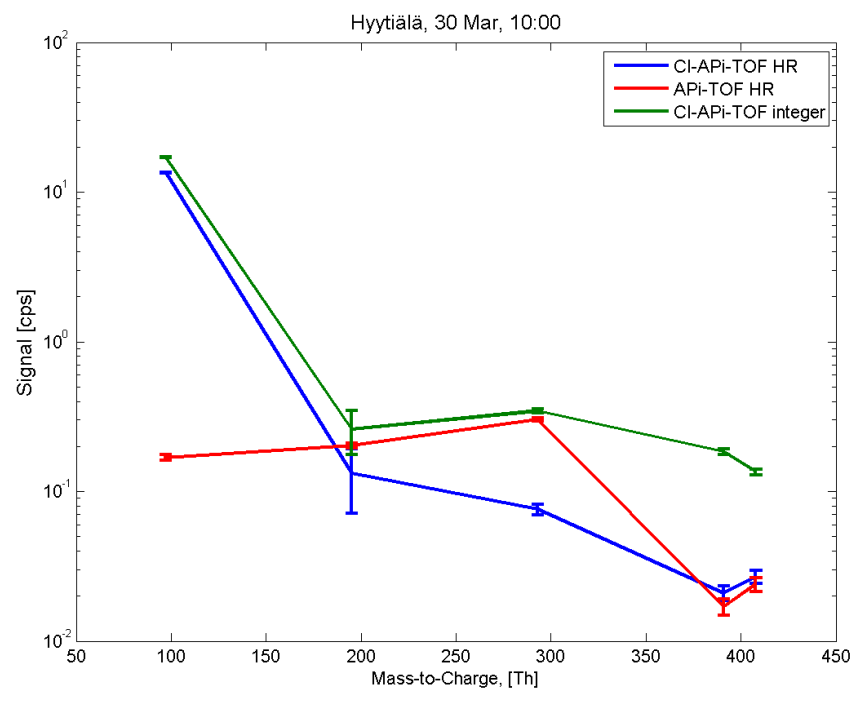

Fig. 4. Total sulphuric acid and cluster high resolution (HR) signals (blue, CI-APi-TOF HR), the contribution of naturally charged ions to the total signal (red, APi-TOF) and CI-APi-TOF integer mass signals (green, CI-APi-TOF integer) are present in this figure. Mass-tocharge ratios in the picture correspond to sulphuric acid monomer (97 Th), dimer (195 Th), trimer (293 Th), tetramer (391 Th) and sulphuric acid tetramer-ammonia cluster (408 Th). Error is calculated using counting statistics. It should be noted that the tetramer CIAPi-TOF values represent an upper limit due to overlapping signals (see text and Fig. 2). Neutral sulphuric acid monomer is the only compound to clearly being charged in the CI-APi-TOF.

monomer concentration reaches $7 \times 10^{6}$ molec $\mathrm{cm}^{-3}$ both days. The coagulation sink (CoagS) for sulphuric acid dimers (calculated from DMPS data with RH-correction and assuming $1.2 \mathrm{~nm}$ mobility diameter, $\mathrm{Ku}$ and Fernandez de la Mora, 2009) during the times of maximum sulphuric acid concentrations on 29 and 30 March is $1.5 \times 10^{-3} \mathrm{~s}^{-1}$ and $0.9 \times 10^{-3} \mathrm{~s}^{-1}$, respectively, assuming that the evaporation rate of dimers is negligible (Petäjä et al., 2011) and that, besides coagulation, the second sink for dimers is the collision limited growth to trimers. In a steady state the production of dimers equals the loss:

$k_{11} \cdot[\text { monomer }]^{2}=\mathrm{CoagS} \cdot[$ dimer $]+k_{21} \cdot[$ dimer $] \cdot[$ monomer $]$

Using collision rates of $k_{11}=3.34 \times 10^{-10} \mathrm{~cm}^{3} \mathrm{~s}^{-1}$ and $k_{21}=3.69 \times 10^{-10} \mathrm{~cm}^{3} \mathrm{~s}^{-1}$ for dimer and trimer formation would result in dimer concentration on the order of 4$5 \times 10^{6} \mathrm{~cm}^{-3}$ which is significantly higher than one could estimate from the data. This discrepancy indicates that though a laboratory system can be saturated with respect to stabilizing compounds leading to near zero evaporation rate of dimers, Hyytiälä air is not necessarily and thus the variation in observed nucleation rates can partly also result from changing concentrations of ternary species. Other possibilities could be that in the ambient atmosphere the oxidized or- ganics rapidly condense on dimers forming compounds that cannot be detected using the present technique.

\section{Conclusions}

We have constructed a nitrate ion based Chemical Ionization Atmospheric Pressure interface Time-Of-Flight mass spectrometer (CI-APi-TOF) and presented ambient measurements of neutral sulphuric acid and its clusters from the atmosphere. We found the CI-APi-TOF a reliable and highly sensitive tool for measurements of low concentrations of atmospheric molecular sulphuric acid. We also measured signals from clusters containing sulphuric acid up to the tetramer with a fraction of tetramers containing one molecule of ammonia. All of the observed cluster peaks were associated with one or more peaks at the same integer mass, and therefore the high mass resolution of the APi-TOF was crucial in the separation of the cluster signal from unknown constituents. Furthermore, most of the observed masses followed a similar diurnal cycle as sulphuric acid, possibly indicating photochemical production pathways. Therefore diurnal behaviour alone could not have been used straightforwardly for concluding the chemical composition and further information is required.

The detected signals from sulphuric acid clusters were found to result, within the measurement accuracy, mostly or purely from naturally charged sulphuric acid clusters formed by ion induced nucleation in the atmosphere. In the case of sulphuric acid monomers, the artefact caused by naturally charged $\mathrm{HSO}_{4}^{-}$was found to be $1-2 \%$ of the total sulphuric acid concentration. Due to ion interferences no reliable data for neutral clusters were obtained. There are several possible reasons for that. First, neutral clusters may not become charged in collisions with nitrate ions, and will thus not be detected. Second, the concentrations of the neutral clusters are possibly not sufficient. If the nucleation process in Hyytiälä was purely or mostly ion-induced or ion-mediated as suggested by Yu and Turco (2011), the absence of neutral clusters at the smallest sizes would be natural as only clusters formed upon recombination would contribute to the concentration of neutral clusters. The detection limit for neutral clusters, assuming the charging probability of cluster is roughly equal to that of the monomer, is of the order of few $10^{4} \mathrm{~cm}^{-3}$ (assuming no contribution from naturally charged clusters and no overlapping peaks in the spectra). In reality, due to mentioned interferences, the true detection limit is somewhat higher and variable. Therefore the existence of neutral clusters - chargeable with $\mathrm{NO}_{3}^{-}$- below concentration of few $10^{4}-10^{5} \mathrm{~cm}^{-3}$ per species cannot be excluded allowing conclusions about the nucleation mechanism to be drawn. However, due to the clear absence of neutral dimers, kinetically limited neutral sulphuric acid nucleation seems implausible. In the presence of naturally charged ions and compounds at the same integer mass the detection limit for 
neutrals is obviously somewhat larger. In future studies the sensitivity of the system will be increased by incorporating an ion filter in front of the instrument to remove the influence of ion clusters.

In terms of sensitivity the performance of our system is comparable to that of Zhao et al. (2010) and Jiang et al. (2011), as well as the system of Petäjä et al. (2011) but the results are contradictory. The reason for this discrepancy is not clear, but certainly the measurement site and environmental parameters as well as the mass spectrometer differed between the experiments. As no reliable signal from neutral sulphuric acid dimers was obtained, it is plausible that, unlike many laboratory systems, atmospheric air is not saturated with respect to stabilizing compounds. This observation will hopefully boost future work on elucidating these stabilizing compounds.

Acknowledgements. Jenni Kontkanen is acknowledged for calculating the coagulation sink and Pauli Paasonen for useful discussions. Mikhail Paramonov, Jonathan Duplissy, Siegfried Schobesberger, Alessandro Franchin, Katrianne Lehtipalo, Hanna Manninen, Pasi Aalto, Silja Häkkinen, Stéphanie Gagné, Mikko Äijälä, Juha Kangasluoma, Emma Järvinen, Erik Herrmann and the personnel of the Hyytiälä forestry field station are acknowledged for help during field measurements. This work was partially funded by Academy of Finland (1251427, 1139656, Finnish centre of excellence 1141135) and European Research Council (ATMNUCLE).

Edited by: F. Yu

\section{References}

Aalto, P., Hämeri, K., Becker, E., Weber, R., Salm, J., Mäkelä, J., Hoell, C., O’Dowd, C., Karlsson, H., Hansson, H.-C., Väkevä, M., Koponen, I. K., Busorius, G., and Kulmala, M.: Physical characterization of aerosol particles during nucleation events, Tellus B, 53B, 344-358, 2001.

Asmi, E., Sipilä, M., Manninen, H. E., Vanhanen, J., Lehtipalo, K., Gagné, S., Neitola, K., Mirme, A., Mirme, S., Tamm, E., Uin, J., Komsaare, K., Attoui, M., and Kulmala, M.: Results of the first air ion spectrometer calibration and intercomparison workshop, Atmos. Chem. Phys., 9, 141-154, doi:10.5194/acp-9-141-2009, 2009.

Benson, D. R., Yu, J. H., Markovich, A., and Lee, S.-H.: Ternary homogeneous nucleation of $\mathrm{H}_{2} \mathrm{SO}_{4}, \mathrm{NH}_{3}$, and $\mathrm{H}_{2} \mathrm{O}$ under conditions relevant to the lower troposphere, Atmos. Chem. Phys., 11, 4755-4766, doi:10.5194/acp-11-4755-2011, 2011.

Berndt, T., Stratmann, F., Sipilä, M., Vanhanen, J., Petäjä, T., Mikkilä, J., Grüner, A., Spindler, G., Lee Mauldin III, R., Curtius, J., Kulmala, M., and Heintzenberg, J.: Laboratory study on new particle formation from the reaction $\mathrm{OH}+\mathrm{SO}_{2}$ : influence of experimental conditions, $\mathrm{H}_{2} \mathrm{O}$ vapour, $\mathrm{NH}_{3}$ and the amine tert-butylamine on the overall process, Atmos. Chem. Phys., 10, 7101-7116, doi:10.5194/acp-10-7101-2010, 2010.

Ehn, M., Junninen, H., Petäjä, T., Kurtén, T., Kerminen, V.-M., Schobesberger, S., Manninen, H. E., Ortega, I. K., Vehkamäki,
H., Kulmala, M., and Worsnop, D. R.: Composition and temporal behavior of ambient ions in the boreal forest, Atmos. Chem. Phys., 10, 8513-8530, doi:10.5194/acp-10-8513-2010, 2010.

Eisele, F. L. and Hanson, D. R.: First results of prenucleation molecular clusters, J. Phys. Chem. A, 104, 830-836, 2000.

Eisele, F. L. and Tanner, D. J.: Measurement of the gas phase concentration of $\mathrm{H}_{2} \mathrm{SO}_{4}$ and methane sulfonic acid and estimates of $\mathrm{H}_{2} \mathrm{SO}_{4}$ production and loss in the atmosphere, J. Geophys. Res., 98, 9001-9010, 1993.

Hanson, D. R. and Eisele, F. L.: Measurement of prenucleation molecular clusters in the $\mathrm{NH}_{3}, \mathrm{H}_{2} \mathrm{SO}_{4}, \mathrm{H}_{2} \mathrm{O}$ system, J. Geophys. Res., 107, 4158, doi:10.1029/2001JD001100, 2002.

Hanson, D. R. and Lovejoy, E. R.: Measurement of the thermodynamics of the hydrated dimer and trimer of sulfuric acid, J. Phys. Chem. A., 110, 9525-9528, 2006.

Iida, K., Stolzenburg, M., and McMurry, P. H.: Effect of Working Fluid on Sub-2 nm Particle Detection with a Laminar Flow Ultrafine Condensation Particle Counter, Aerosol Sci. Technol., 43, 81-96, 2009.

Jiang, J. K., Chen, M. D. Kuang, C. A., Attoui, M., and McMurry, P. H.: Electrical Mobility Spectrometer Using a Diethylene Glycol Condensation Particle Counter for Measurement of Aerosol Size Distributions Down to $1 \mathrm{~nm}$, Aerosol Sci. Technol., 45, 510-521, 2011.

Junninen, H., Ehn, M., Petäjä, T., Luosujärvi, L., Kotiaho, T., Kostiainen, R., Rohner, U., Gonin, M., Fuhrer, K., Kulmala, M., and Worsnop, D. R.: A high-resolution mass spectrometer to measure atmospheric ion composition, Atmos. Meas. Tech., 3, 10391053, doi:10.5194/amt-3-1039-2010, 2010.

Kirkby, J., Curtius, J., Almeida, J., Dunne, E., Duplissy, J., Ehrhart, S., Franchin, A., Gagné, S., Ickes, L., Kürten, A., Kupc, A., Metzger, A., Riccobono, F., Rondo, L., Schobesberger, S., Tsagkogeorgas, G., Wimmer, D., Amorim, A., Bianchi, F., Breitenlechner, M., David, A., Dommen, J., Downard, A., Ehn, M., Flagan, R. C., Haider, S., Hansel, A., Hauser, D., Jud, W., Junninen, H., Kreissl, F., Kvashin, A., Laaksonen, A., Lehtipalo, K., Lima, J., Lovejoy, E. R., Makhmutov, V., Mathot, S., Mikkilä, J., Minginette, P., Mogo, S., Nieminen, T., Onnela, A., Pereira, P., Petäjä, T., Schnitzhofer, R., Seinfeld, J. H., Sipilä, M., Stozhkov, Y., Stratmann, F., Tome, A., Vanhanen, J., Viisanen, Y., Vrtala, A., Wagner, P. E., Walther, H., Weingartner, E., Wex, H., Winkler, P. M., Carslaw, K. S., Worsnop, D. R., Baltensperger, U., and Kulmala, M.: Role of sulphuric acid, ammonia and galactic cosmic rays in atmospheric aerosol nucleation, Nature, 476, 429-433, 2011.

$\mathrm{Ku}, \mathrm{B}$. K. and Fernandez de la Mora, J.: Relation between electrical mobility, mass and size for nanodrops $1-6.5 \mathrm{~nm}$ in diameter in air, Aerosol Sci. Technol., 43, 241-249, 2009.

Kulmala, M., Riipinen, I., Sipilä, M., Manninen, H. E., Petäjä, T., Junninen, H., Dal Maso, M., Modras, G., Mirme, A., Vana, M., Hirsikko, A., Laakso, L., Harrison, R. M., Hanson, I., Leung, C., Lehtinen, K. E. J., and Kerminen, V.-M.: Toward direct measurement of atmospheric nucleation, Science, 318, 89-92, 2007.

Kulmala, M., Riipinen, I., Nieminen, T., Hulkkonen, M., Sogacheva, L., Manninen, H. E., Paasonen, P., Petäjä, T., Dal Maso, M., Aalto, P. P., Viljanen, A., Usoskin, I., Vainio, R., Mirme, S., Mirme, A., Minikin, A., Petzold, A., Hõrrak, U., Plaß-Dülmer, C., Birmili, W., and Kerminen, V.-M.: Atmospheric data over a solar cycle: no connection between galactic cosmic rays and new particle formation, Atmos. Chem. Phys., 10, 1885-1898, 
doi:10.5194/acp-10-1885-2010, 2010.

Kurtén, T., Loukonen, V., Vehkamäki, H., and Kulmala, M.: Amines are likely to enhance neutral and ion-induced sulfuric acid-water nucleation in the atmosphere more effectively than ammonia, Atmos. Chem. Phys., 8, 4095-4103, doi:10.5194/acp-8-4095-2008, 2008.

Kurtén, T., Petäjä, T., Smith, J., Ortega, I. K., Sipilä, M., Junninen, H., Ehn, M., Vehkamäki, H., Mauldin, L., Worsnop, D. R., and Kulmala, M.: The effect of $\mathrm{H}_{2} \mathrm{SO}_{4}-$ amine clustering on chemical ionization mass spectrometry (CIMS) measurements of gas-phase sulfuric acid, Atmos. Chem. Phys., 11, 3007-3019, doi:10.5194/acp-11-3007-2011, 2011.

Manninen, H. E., Nieminen, T., Riipinen, I., Yli-Juuti, T., Gagné, S., Asmi, E., Aalto, P. P., Petäjä, T., Kerminen, V.-M., and Kulmala, M.: Charged and total particle formation and growth rates during EUCAARI 2007 campaign in Hyytiälä, Atmos. Chem. Phys., 9, 4077-4089, doi:10.5194/acp-9-4077-2009, 2009.

Mauldin III, R. L., Tanner, D., Heath, J., Huebert, B., and Eisele, F.: Observations of $\mathrm{H}_{2} \mathrm{SO}_{4}$ and MSA during PEM-Tropics-A, J. Geophys. Res., 104, 5801-5816, 1999.

Merikanto, J., Spracklen, D. V., Pringle, K. J., and Carslaw, K. S.: Effects of boundary layer particle formation on cloud droplet number and changes in cloud albedo from 1850 to 2000, Atmos. Chem. Phys., 10, 695-705, doi:10.5194/acp-10-695-2010, 2010.

O’Dowd, C. D., Jimenez, J. L., Bahreini, R., Flagan, R. C., Seinfeld, J. H., Hämeri, K., Pirjola, L., Kulmala, M., Jennings, S. G., and Hoffmann, T.: Marine aerosol formation from biogenic iodine emissions, Nature, 417, 632-636, 2002.

Paasonen, P., Nieminen, T., Asmi, E., Manninen, H. E., Petäjä, T., Plass-Dülmer, C., Flentje, H., Birmili, W., Wiedensohler, A., Hõrrak, U., Metzger, A., Hamed, A., Laaksonen, A., Facchini, M. C., Kerminen, V.-M., and Kulmala, M.: On the roles of sulphuric acid and low-volatility organic vapours in the initial steps of atmospheric new particle formation, Atmos. Chem. Phys., 10, 11223-11242, doi:10.5194/acp-10-11223-2010, 2010.
Petäjä, T., Sipilä, M., Paasonen, P., Nieminen, T., Kurtén, T., Ortega, I. K., Stratmann, F., Vehkamäki, H., Berndt, T., and Kulmala, M.: Experimental Observation of Strongly Bound Dimers of Sulfuric Acid: Application to Nucleation in the Atmosphere, Phys. Rev. Lett., 106, 228302, doi:10.1103/PhysRevLett.106.228302, 2011.

Sipilä, M., Lehtipalo, K., Kulmala, M., Petäjä, T., Junninen, H., Aalto, P. P., Manninen, H. E., Kyrö, E.-M., Asmi, E., Riipinen, I., Curtius, J., Kürten, A., Borrmann, S., and O'Dowd, C. D.: Applicability of condensation particle counters to measure atmospheric clusters, Atmos. Chem. Phys., 8, 4049-4060, doi:10.5194/acp-8-4049-2008, 2008.

Sipilä, M., Berndt, T., Petäjä, T., Brus, D., Vanhanen, J., Stratmann, F., Patokoski, J., Mauldin III, R. L., Hyvärinen, A.-P., Lihavainen, H., and Kulmala, M.: The role of sulphuric acid in atmospheric nucleation, Science, 327, 1243-1246, 2010.

Vanhanen, J., Mikkilä, J., Lehtipalo, K., Sipilä, M., Manninen, H. E., Siivola, E., Petäjä, T. and Kulmala, M.: Particle size magnifier for nano-CN detection, Aerosol Sci. Technol., 45, 533-542, 2011.

Weber, R. J., Marti, J. J., McMurry, P. H., Eisele, F. L., Tanner, D. J., and Jefferson, A.: Measured atmospheric new particle formation rates: Implication for nucleation mechanisms, Chem. Eng. Commun., 151, 53-64, doi:10.1080/00986449608936541, 1996.

Yu, F. and Turco, R.: Case studies of particle formation events observed in boreal forests: implications for nucleation mechanisms, Atmos. Chem. Phys., 8, 6085-6102, doi:10.5194/acp-86085-2008, 2008.

Yu, F. and Turco, R. P.: The size-dependent charge fraction of sub-3$\mathrm{nm}$ particles as a key diagnostic of competitive nucleation mechanisms under atmospheric conditions, Atmos. Chem. Phys., 11, 9451-9463, doi:10.5194/acp-11-9451-2011, 2011.

Zhao, J., Eisele, F. L., Titcombe, M., Kuang, C., and McMurry, P. H.: Chemical ionization mass spectrometric measurements of atmospheric neutral clusters using the cluster-CIMS, J. Geophys. Res., 115, D08205, doi:10.1029/2009JD012606, 2010. 